https://doi.org/10.36909/jer.v9iICRIE.11673

\title{
Absorber Type Optimization for Night-Shift Operation of Solar Air Heater
}

\author{
Hardi A. M. Rasul *, Idress A. Hamakhan* and Ali M. Ibrahim** \\ *College of Engineering, Salahaddin University-Erbil, Iraq \\ **Ministry of Electricity (KRG), Iraq \\ *Email: hardi.m.rasul@su.edu.krd; Corresponding Author.
}

\begin{abstract}
In the current study, the effect of using heat storage materials aimed at the night shift operation was studied by simulation tools. The Finite Volume Method (FVM) is used as a method to discretize the governing equations in the 2-D domain, and the RNG K- turbulence model is applied for simulation. The effect of absorption type based on five different materials such as Aluminum, Water, Asphalt, Graphite, and Sand on the performance of solar air heaters $(\mathrm{SAH})$ is carried out thermally. The results show that the optimum material to obtain the maximum difference in temperature $(38.32 \mathrm{~K})$ between the absorber and the surrounding occurs once the asphalt is used, while the sand is the worst case, which is $(31.71 \mathrm{~K})$. Following, the focus is on the best absorber for night time operation. The Lumped Parameter Analysis is applied to the time required to dissipate the heat energy from the storage layer to reduce it to the assumed final temperature of a 5-degree difference (higher) than the ambient. After solving the transient equation, it is found that water can operate the system for a longer period (4.31 hrs.) as well as Graphite can operate the system for a shorter period $(0.46 \mathrm{hrs}$.). Then ten different velocities in the entry section are used to consider the influences on the system performance. The results show that the velocity has a significant effect on the outlet temperature and operation period for night time.
\end{abstract}

Keywords: CFD; Optimum Thermal storage absorber; Operation after sunset; Outlet temperature;

\section{INTRODUCTION}

Solar air heaters are modest systems used for solar radiation incidents to produce solar energy for various uses. The solar radiation from the solar collector is converted into heat energy in the air and the air is dispensed to operate (Piao, Hauptmann et al. 1994). The solar air heater, which is based on the energy of the radiation from the sun, is a certain system used for heating. (Esen, Ozgen et al. 2009). Because of air's lower transfer of heat by convection, which presents a non-considerable transfer of energy in the form of heat from the absorber plate. (Saini and Singal 2007, Bhushan and Singh 2010). A mass-air study ranging from 0.02 to $0.137 \mathrm{~kg} / \mathrm{s}$ was investigated. With a further number of fins, the system performance increases and entropy production were in inverse proportion 
to the number of fins. (Naphon 2005). (Priyam and Chand 2016) studied the wavy finned absorber effect on the system performance both thermally and thermo-hydraulically. The wired surface packed bed solar air system has been investigated to evaluate the effects on the thermal performance by (Chouksey and Sharma 2016). (Sahu and Prasad 2016) presented results demonstrate that it is one of the imperative approaches to assessing system inefficiency. The significant incidents that increased the energy transfer rate and improved the performance are the detachment of flow, development of secondary flow and the creation of vortices (Bhushan and Singh 2012). The effect of most important parameters, such as Reynolds and Nusselt number, friction factor, and global thermohydraulic performance parameters, are surveyed and argued. (Yadav and Kaushal 2013) studied the influence of transfer of heat and friction aspects of turbulent flow of air. The round extension irregularity is implemented in the form of a sharp-edged arc heated plate on the rectangular duct system for air flow. Several Reynolds No. in between 3600 to $18000, \mathrm{P} / \mathrm{e}$ in the assortment of 12 to 24 , e/D in between 0.015 to 0.030 , and extension inclinati on angle in between 45 to 75 were conducted during the experimentation. An important improvement in both the transfer of heat and frictionis shown as 2.89 and 2.93 times as equated with the smoother absorber. Providing unreal roughness on the absorber plate to advance the thermo-hydraulic performance of SAH was considered by (Layek 2019). Several parameters have been carefully chosen as design variables of the single V-shape rib for the performance investigation of SAH solar air heaters by (Rana, Silori, Maithani \& Chamoli, 2018) such as comparative roughness pitch, $\mathrm{P}$ / e=6-12; Reynolds number, 3800-18000, comparative roughness height, e / D = 0,042, and the attack angle, $\alpha=30^{\circ}-75^{\circ}$. (Gawande, Dhoble et al. 2014). The ANSYS FLUENT 12.1 code was used for a two-dimensional Computational Fluid Dynamic (CFD) simulation as a solver for the RNG k- turbulence model. For the range of limitations, the peak value of the thermal improvement factor was 1,656. (A. S.Yadav and J. L. Bhagoria 2013). (Muhammed and Atrooshi 2019) used ANSYS Fluent to find the optimum dimensions of SCPP. The simulation study of laminar and turbulent flow with different boundary conditions was carried out for the solar chimney power plant by (Zamora and Kaiser 2009). However, using thermal storage martials can play an important role in facing this problem to benefit the sun's energy at night. Thus, using high heat capacity materials such as paraffin wax as a Phase Change Material (PCM) is a significant way to store energy and reuse it at the desired time. (Farid, Khudhair et al. 2004). Phase change materials have the ability to absorb and discharge a great amount of energy at an almost stable temperature during gain and release processes. (Tyagi, Panwar et al. 2012). (Dutil, Rousse et al.2011) showed that, in order to achieve a good amount of absorbed energy density and the capability to collect additional latent heat at a stable temperature, PCMs can be a crucial way that offers a good impact.(Bal, Satya et al. 2011). (Wadhawan, Dhoble et al. 2018) They investigated the comparison of the SAH outlet temperature including and non-including thermal storage by manufacturing a thermal energy storage device (TESD). An analysis was 
conducted via a lattice of steel wires for the absorber (Omojaro \& Aldabbagh, 2010). (Ozgen, Esen et al. 2009) experimentally studied the preparation of estimating the thermal characteristics of a double-stream solar air heater. The calculation of the impact of baffles and fines on SAH's performance and the absorber flat as a single upward type pass has been taken into account by (Mohammadi \& Sabzpooshani, 2013). The increase in connecting fins and baffles has been found to increase the outlet temperature. The three-dimensional analysis was performed by (S. Kumar \& Saini, 2009) on the basis of a CFD for the SAH. The flow and amount of the transferred heat of fluid in the system was simulated using a turbulence model, $\mathrm{k}-\varepsilon$. On the whole, the comprehensive enhancement ratio is discussed to specify the effects of roughness. (Pashchenko 2018) carried out a study of the impact of the design of the finstep and variable Reynolds number on heat transfer processes. The study was implemented by ANSYS Fluent Solver with an integrated solar calculator for the city of Samara, Russia. The results showed that using a finned light absorbing surface is 1.91 for $\operatorname{Re}=1500$, leading to higher thermo-aero-dynamic characteristics, while the lowest test fin pitch is $30 \mathrm{~mm}$.

The literature review shows that a significantly rare number of articles have studied various thermal storage types for the absorber plate, such as water, clay, sand, and asphalt. It is also found that most of them use PCMs as thermal storage. Moreover, it can be guessed that insufficient research has so far evaluated the period of working SAH after sunshine. This method can be used to operate the system at night. Therefore, this study aims to find a solution to serve the SAHs during the night time using a novel CFD study. The ANSYS Fluent tools, v16.0, are used to build the model and to simulate the output behavior of the model.

\section{MATHEMATICAL ANALYSIS AND CFD MODELING}

\section{MATHEMATICAL ANALYSIS}

Mass, energy conversion, and momentum are numerically solved in Computational Fluid Dynamics (CFD). The governing equations are solved simultaneously. The summary of equations is:

$$
\frac{\partial}{\partial x i}=(\rho u i)=0
$$

\section{Momentum equation:}

$$
\frac{\partial}{\partial x i}=(\rho u i u j)=-\frac{\partial p}{\partial x i}+\frac{\partial}{\partial x}\left[\mu\left(\frac{\partial u i}{\partial x j}+\frac{\partial u j}{\partial x i}\right)\right]+\frac{\partial y}{\partial x j}(\underset{-\rho u \imath u j}{\longrightarrow})
$$

\section{Energy equation:}

$$
\frac{\partial}{\partial x i}=(\rho u i T)=\frac{\partial}{\partial x j}\left((\Gamma+\Gamma t) \frac{\partial T}{\partial x j}\right)
$$


Where:

Where $x_{i}$ is a, $u_{i}, u^{\prime}{ }_{i}, \rho, P, \mu$, and $T$ are co-ordinate systems, velocity part of flow, fluctuation, density, pressure, viscosity coefficient, and temperature respectively. While $\Gamma$ is the molecular thermal diffusivity, and $\Gamma_{t}$ is the turbulent thermal diffusivity, which can be considered by these equations (Qader, Supeni et al. 2019):

$$
\Gamma=\frac{\mu_{t}}{P r} \quad \text { and } \quad \Gamma_{t}=\frac{\mu_{t}}{P r_{t}}
$$

\section{Temperature Distribution}

The collector's outlet air temperature can be achieved by:

$$
\frac{\theta_{f o}-\theta_{a}-\left(\frac{s}{U_{O L}}\right)}{\theta_{f i}-\theta_{a}-\left(\frac{s}{U_{O L}}\right)}=\exp \left(-\frac{A_{C S} U_{O L} F_{C}^{\prime}}{m c_{p}}\right)
$$

By solving the following equations, the values of the absorber's mean temperature and the back-plate can be calculated. (Rai, Chand et al. 2018):

$$
\theta_{n}-\theta_{f}=\frac{s\left(U_{b t}+h_{b a} \emptyset_{f i n}+h_{r a}\right)-\left(\theta_{f}-\theta_{a}\right) *\left(U_{b t} U_{t l}+U_{b t} U_{r a}+U_{t l} h_{b a} \emptyset_{f i n}+U_{t l} h_{r a}\right)}{\left(U_{t l}+h_{a a}+h_{r a}\right)\left(U_{b t}+h_{b a} \emptyset_{f i n}+h_{r a}\right)-h_{r a}^{2}}
$$

and

$$
\theta_{2}-\theta_{f}=\frac{h_{r a} S-\left(\theta_{f}-\theta_{a}\right) *\left(U_{b t} U_{t l}+U_{b t} U_{r a}+U_{t l} h_{r a}+U_{b t} h_{a a}\right)}{\left(U_{t l}+h_{a a}+h_{r a}\right)\left(U_{b t}+h_{b a} \emptyset_{f i n}+h_{r a}\right)-h_{r a}^{2}}
$$

The temperature of the average air stream can be expressed by (Duffie and Beckman 2013):

$$
\theta_{f}=\theta_{f i}+\left(\frac{\frac{Q u g}{A_{S C}}}{A_{H R} U_{O L}}\right)\left(1-\frac{F_{H R}}{F_{c}^{\prime}}\right)
$$

The absorbed solar is estimated by:

$$
S=\left(\tau_{c} \tau_{a}\right) I_{o}
$$

While, the energy gain is expressed as:

$$
S=A_{S C} F_{H R}\left(S-U_{O L}\left(\theta_{f i}-\theta_{a}\right)\right)
$$

\section{CFD SIMULATION}

Solving the equations of mass, momentum, and energy equations. A CFD code based on the Finite Volumes method was used. The discretization of the governing equations in the second order Upwind scheme was implemented. The 
standard scheme was performed for Pressure-Interpolation, while the SIMPLE algorithm for coupling between velocity and pressure was selected. As well, in the current study, the turbulence k- (epsilon) model is used, which is based on the Re-Normalization (RNG) group theory (Xie, Liu et al. 2013, Kumar and Kumar 2017).

\section{VERIFICATION OF THE MODEL AND COMPUTATIONAL DOMAIN}

The process encompasses checking the results of the simulation against the previous numerical work to validate the results and identify the discrepancies. The model results are compared with other investigation results (Karwa and Maheshwari 2009). Research on the punctured baffles 5-10 was led by data collection for the duct carrying two numbers of fully punctured baffles. The flow analysis is based on the Nusselt number ratios; $\mathrm{Nu} / \mathrm{Nus}$ is used to validate the simulation method by FLUENT for modeling a solar air heater. The approximate similar geometry is used for comparisons with (Karwa and Maheshwari 2009). The obtained results from the current simulation model are compared graphically with the experimental results as shown in figure 1. A good quantitative verification was acquired between the exploratory information of the experimental model and the simulation results.

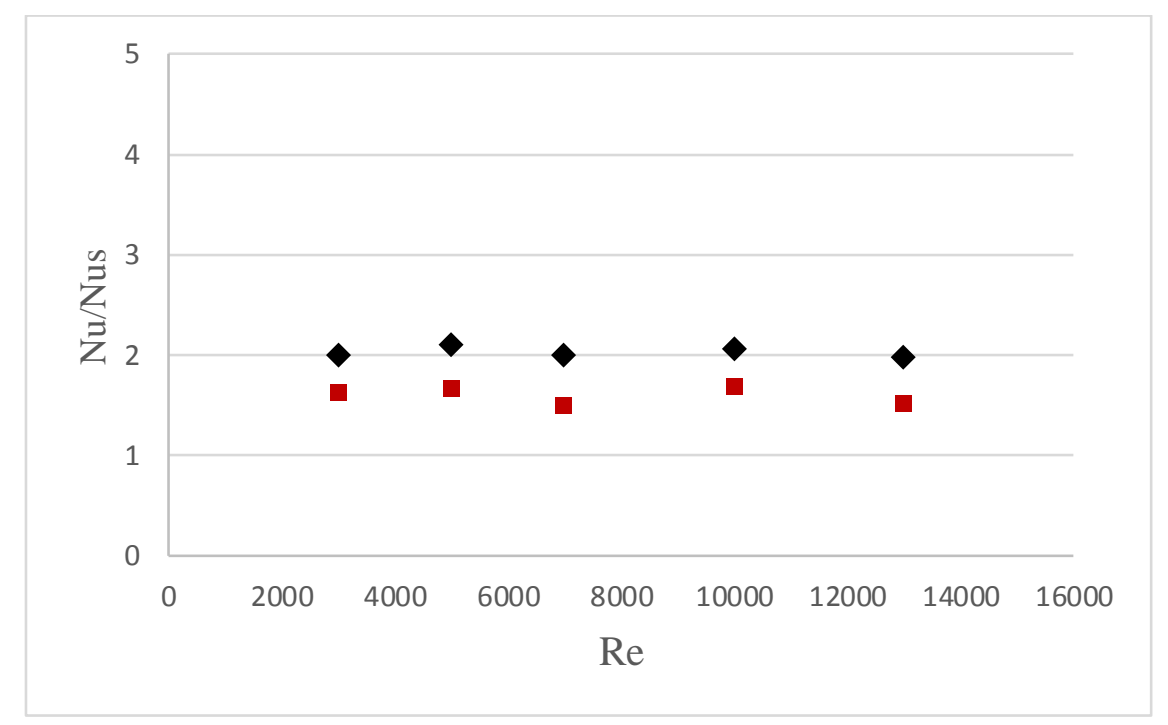

Figure 1 Comparison between $\mathrm{Nu} / \mathrm{Nu}_{\mathrm{s}}$ of the present models with experimental results.

As shown in Fig.2, the inlet, heated (absorber) and drain parts of the rectangular duct flow network are included. The inlet and outlet length have been assigned to decrease the impact of the investigated segment in accordance with the ASHRAE specification (Specification, 2003). In addition, for the SAH pipe including (L1, L2 \& L3), an overall length of $640 \mathrm{~mm}$ was appropriate. The aspect ratio of the duct width to height $(\mathrm{W} / \mathrm{H})$ was not changed according to the standard. 
Figure 2 Two-

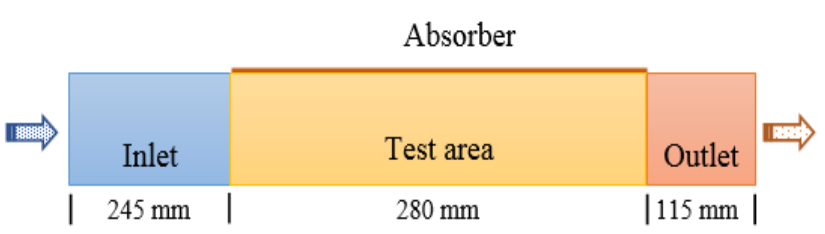

dimensional System

layout.

\section{MESHING PROCESS}

Since the ANSYS package is based on the Finite-Volume Method, designed geometry needs to be meshed. The solution accuracy of any problem depends on the cell size (i.e. mesh size). A smaller mesh size leads to a more accurate solution.(Kumar and Saini 2009) studied the fluid flow and characteristics of energy transfer (Heat focused) of SAH based on the simulation by CFD. Using scratched duct provided with unreal roughness in arc shaped geometry, the investigation was carried out by using FLUENT Software codes. The different available models of turbulence results have been compared with the empirical correlation of Dittus - Boelter for Nusselt number. Depending on the software results, the following outcomes were drawn: firstly, the results of the Renormalization-group (RNG) k- (Epsilon) were found in good arrangement with all other used turbulence models, and secondly, the non-uniform mesh was acceptable for 2dimensional SAHs. FLUENT ANSYS (v16.1) with k- (Epsilon) turbulence model renormalization group and non-uniform mesh was designated for computational domain analysis of SAH by (Qader, Supeni et al. 2019). Additionally, ten element numbers were considered to find the optimum

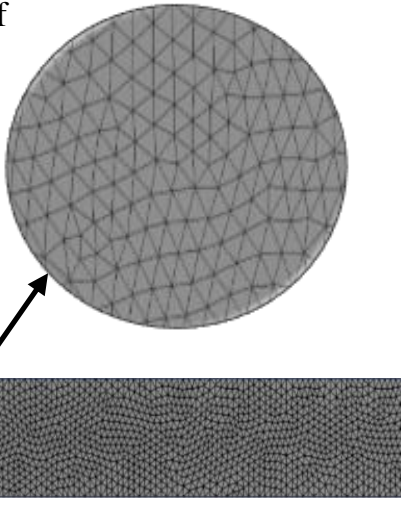
grid number against the Nusselt number. They graphically presented that entire mesh elements numbers higher than 148281 show the similar normal Nusselt number result. Therefore, for the current study, the characteristics of the meshing and turbulence model are exposed in table-1 and fig-3.

Table 1 CFD Simulation certain criteria.

\begin{tabular}{|l|l|}
\hline Geometry & 2-Dimensional layout \\
\hline Mesh & $\begin{array}{l}\text { Non-uniform type with } 160837 \text { elements and } \\
32824 \text { nodes }\end{array}$ \\
\hline $\begin{array}{l}\text { Turbulence } \\
\text { model }\end{array}$ & Renormalization-group (RNG) $k-\varepsilon$ model \\
\hline
\end{tabular}

Figure 3 Meshed Geometry. 


\section{SOLUTION CONTROL AND BOUNDARY CONDITIONS}

In this article, the uniform heat flux of $1000 \mathrm{Watt} / \mathrm{m}^{2}$ was kept at the top face of the heated part, while for the inlet and outlet, constant velocity and constant pressure outlet boundary conditions were considered. The discretization of equations is a significant phase and it is done using the second order upwind method. The Simple Algorithm was selected as a Pressure-Velocity (P-V) coupling scheme, since simple calculation is a generally utilized numerical method to solve the Naiver-Stoke equations. It's an acronym for Semi-Implicit method for pressure linkedequation. ANSYS Fluent provides comprehensive modeling capabilities for a wide range of incompressible and compressible, laminar and turbulent fluid flow problems. Steady-state or transient analyses can be performed. (Fluent 2013).

The solution convergence can be accessed by placing the residuals of all variables below the desired value. For every one-order residual decrease from $1 \times 10^{-1}$ to $1 \times 10^{-7}$ as illustrated in fig.4, the convergence history is controlled. It was obvious that $1 \times 10^{-5}$ residuals were appropriate for indicating solution convergence, and further iteration was not required, since no change was observed after testing the results. Thus, the value of $1 \times 10^{-5}$ residual has been implemented for the present investigation.

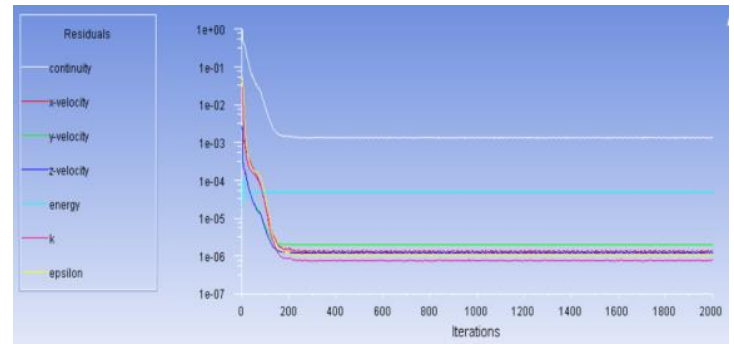

Figure 4 Convergence for residuals criteria.

\section{RESULTS AND DISCUSSION}

\section{EFFECT OF ABSORPTION MATERIALS ON THE OUTLET TEMPERATURE (USING HEAT}

\section{ABSORBING MATERIALS)}

The surface temperature of the asphalt can increase to more than seventy degrees Celsius in the summer seasons. That influences an increase in the temperature of the air above, which is commonly identified as the heat island effect (Berdahl, Akbari et al. 2008). Water possibility of use as a thermal storage material for a wide range of applications(Ibrahim, Ilinca et al. 2008), because of many factors such as, high heat capacity, non-toxicity, existing everywhere and it's cheap. (Py, Olives et al. 2001) Suggested a graphite compound material as a phase change material, where the PCM is entrenched inside a graphite matrix. (Schlipf, Schicktanz et al. 2015) deliberate the opportunity of applying sand in packed bed as storage medium for getting high storage value of heat while high temperature thermal applicable. They presented that; the sands have the capability to present the absorption of potential energy storage for temperatures up to $550{ }^{\circ} \mathrm{C}$. In present study, the capability of five different types of Solar Thermal Energy Storage materials as mentioned above and thermal energy storage systems that are now in use is shown. The influence of solar thermal energy storage materials on the operation of SAH during the night- 
time are discussed and analyzed. Moreover, the specifications of the fluid and the plate of the absorbers are tabulate $\mathrm{d}$ in table 2. The presented data was taken from (Kothandaraman 2004, McEligot, Swank et al. 2016), which worked experimentally to find the optimum properties of several materials

Table-2. Material properties at $\left(27^{\circ} \mathrm{C}\right)$ according to (Kothandaraman 2004, McEligot, Swank et al. 2016)

\begin{tabular}{|c|c|c|c|c|c|c|}
\hline \multirow[t]{2}{*}{ Properties } & \multicolumn{6}{|l|}{ Martials } \\
\hline & $\begin{array}{l}\text { Air } \\
\text { (Working } \\
\text { Fluid) }\end{array}$ & Water & Asphalt & Graphite & Sand & Aluminum \\
\hline Density $\left(\mathrm{kg} / \mathrm{m}^{3}\right)$ & 1.225 & 995 & 2115 & 1.8885 & 1515 & 2719 \\
\hline $\begin{array}{l}\text { Thermal Conductivity } \\
\left(\mathrm{W} / \mathrm{m}^{2} \cdot \mathrm{K}\right)\end{array}$ & 0.0242 & 0.628 & 0.062 & 133.02 & 0.27 & 202.4 \\
\hline $\begin{array}{l}\text { Specific heat capacity } \\
(\mathrm{J} / \mathrm{kg} \cdot \mathrm{k})\end{array}$ & 1006.43 & 4178 & 920 & 726.19 & 800 & 871 \\
\hline Viscosity $\left(\mathrm{Ns} / \mathrm{m}^{2}\right)$ & $1.7894 \mathrm{e}^{-5}$ & - & - & - & - & - \\
\hline
\end{tabular}

This section investigates the effect of absorber materials with different thermal absorption effects on the air temperature escaping the system. As mentioned above, the same geometry dimensions for different materials were utilized as shown in table 2. For this purpose, the two-dimensional geometry is considered for simulation by ANSYS Fluent 16.0. The set operation conditions are: Homogenous heat flux (i.e. $1000 \mathrm{~W} / \mathrm{m} 2$ ) for the absorber, uniform velocity of $0.68 \mathrm{~m} / \mathrm{s}$ (Chaube, Sahoo et al. 2006), The outlet pressure equals the environmental pressure, and no slip wall boundary conditions are used for the analysis, together with the thickness of the absorber plate is assumed as $1 \mathrm{~cm}$. First of all, the simulation was done for an aluminum absorber plate and the outlet temperature compared with experimental investigation by (Chaudhari, Makwana et al. 2014) for several solar intensities as a verification. The results demonstrate a good quantitative acquired with the experimental results, as illustrated in figure 5. 


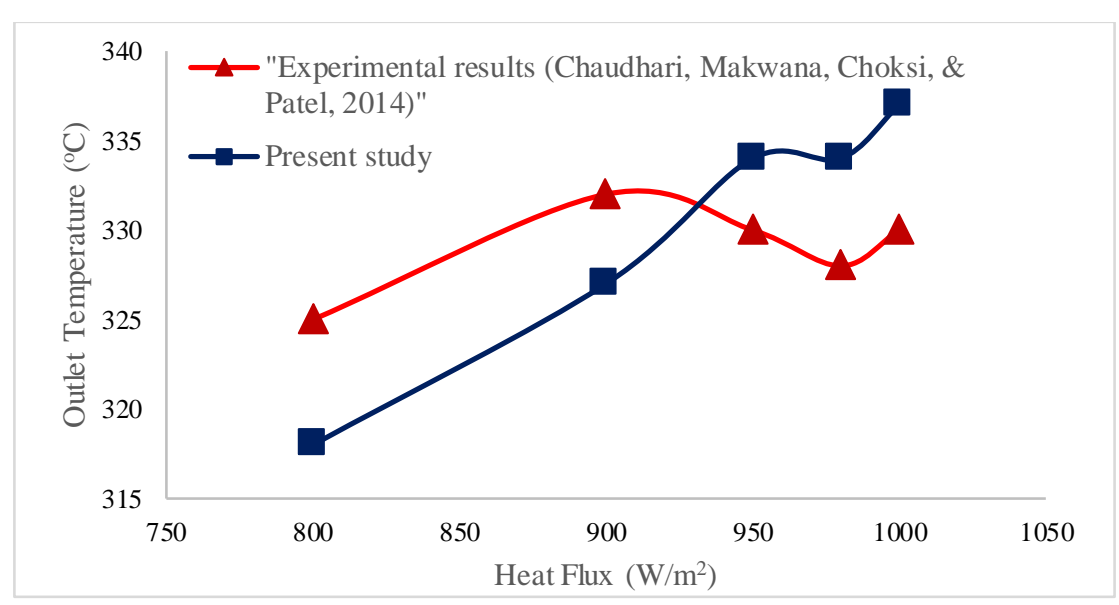

Figure 5 Comparison between the simulation results and experimental data.

Figs. 6 (a)-(e) present the influence of various absorber plates on the temperature contours at an inlet velocity of $0.68 \mathrm{~m} / \mathrm{s}$. From the figures, it is evident that for all absorber types, the maximum heat storage or peak temperature is located at the bottom layers of the absorber plates.

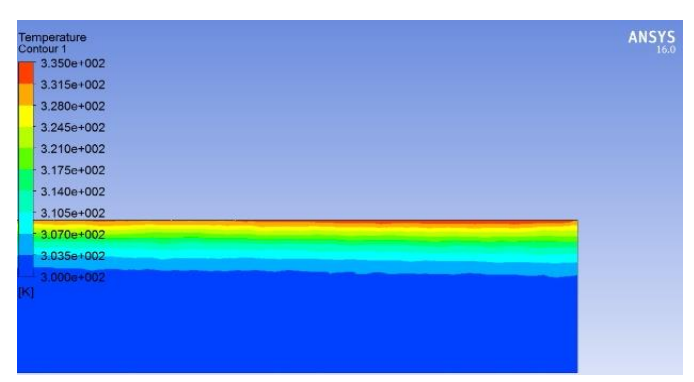

(a)

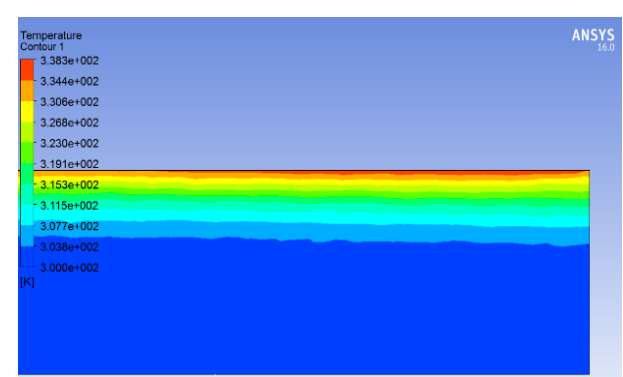

(b)

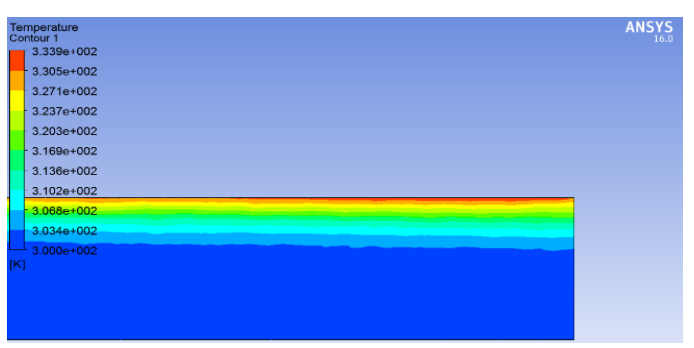

(c)

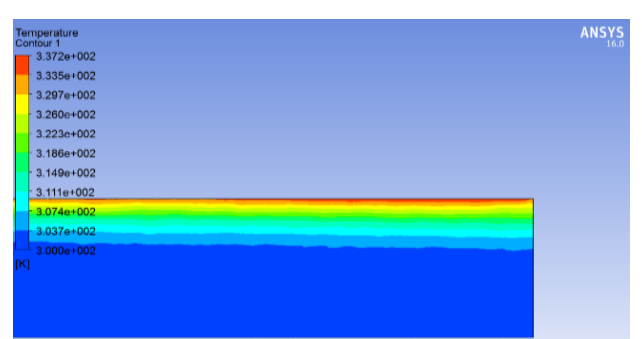

(d)

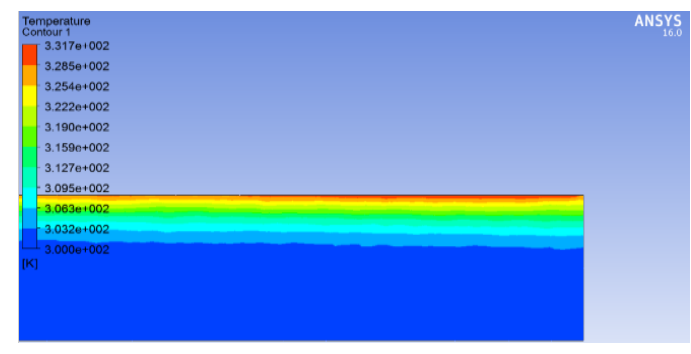

(e)

Figure 6. The contour of Temperature (a) Aluminum, (b) Asphalt, (c)Water, (d)Graphite, and (e) Sand. 
Additionally, Fig. 7. illustrates the effect of varying the absorber materials of SAH on the outlet temperature. The thermal heat storage materials have a significant effect on heating the air through the system. As a result, it can be seen that the exit temperature reaches its maximum value $(338.32 \mathrm{~K})$ when asphalt is used as an absorber. The second one is realized when graphite is considered and the exit temperature decreases to ( $337.2 \mathrm{~K})$. Afterward, the aluminum and water transfer a good quantity of heat to the air and its outlet spreads to around (335.12 K and 333.91 $\mathrm{K})$ respectively. Finally, it is seen from the figure that the sand is the worst case, according to the quality of the working fluid (air) which the temperature is $(331.71 \mathrm{~K})$. The obtained data of the present work is compared with the investigation of(Pretorius 2007). He used several ground materials for a solar chimney system and indicated that graphite and water were the best two materials for improving thermal storage.

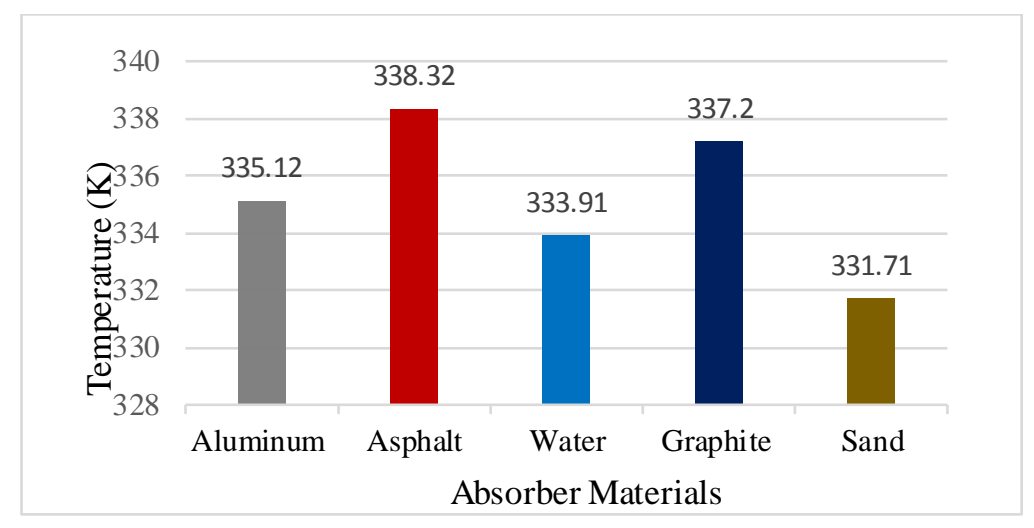

Figure 7 Variation of outlet temperature for different absorber materials.

\section{DURATION OF MAINTAINING EFFECTIVE TEMPERATURE AFTER SUNSET FOR DIFFERENT ABSORBER MATERIALS.}

This part is aimed at studying the effect of thermal storage absorber materials on the continued operation of the solar air during the night shift. Thus, the time required to dissipate the heat energy of the storage layer is calculated until the temperature of the absorber is reduced to an assumed final temperature of 5 -degree difference (higher) than the ambient. Here, the Lumped Parameter Analysis equation-17. is used to evaluate the beneficial operation time after sunset by assuming constant thermal properties (i.e. at $27^{\circ} \mathrm{C}$ ) for the storage material throughout. $\frac{T-T_{\text {ambient }}}{T_{\text {initial-T } T_{\text {ambient }}}}=e^{\left(-\frac{h A_{S}}{\rho V c} \tau\right)}$ 
Where: $T$ is the layer temperature at time $(\tau), T_{\text {Ambient }}$ is the surrounding temperature, $T_{\text {initial }}$ is the initial temperature of the layer, $h$ is the convection heat transfer coefficient $\left(\frac{W}{m^{2} \cdot K}\right), A_{s}$ is the surface area of the absorber $\left(\mathrm{m}^{2}\right), \rho$ is the density of the storage $\left(\frac{\mathrm{kg}}{\mathrm{m}^{3}}\right), \mathrm{V}$ is the volume $\left(\mathrm{m}^{3}\right)$ and $(\tau)$ is time $(\mathrm{sec})$.

The results shown in fig. 8 indicate that, after solving the above transient equation, it was found that water could operate the system for a longer period, after that asphalt could operate the system for a shorter period. Although, on the other hand, the graphite lost the absorbed thermal energy faster than the others because of its lower density. However, the most common absorber type, for example, aluminum, can also operate the system for a good period of time (i.e. 2.45 hours). Finally, the two mentioned materials, water and asphalt, are applicable for the heated plate of SAH instead of other types of material, because they are available everywhere in sufficient quantities.

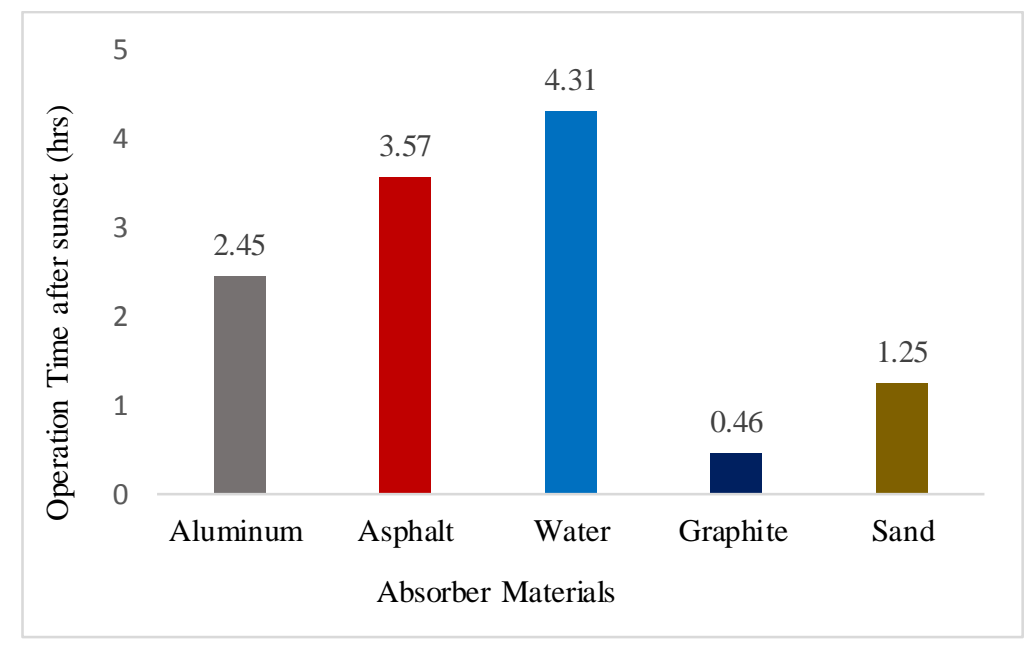

Figure 8 Duration of SAH after sunset for different storage materials.

\subsection{Effect of inlet velocity on the outl et temperature and the night time duration.}

The different inlet velocity in the range of $0.68 \mathrm{~m} / \mathrm{s}$ to $3.4 \mathrm{~m} / \mathrm{s}$ has been studied independently for constant relative absorber heat flux value $(1000 \mathrm{w} / \mathrm{m} 2)$. The effect of inlet velocity on the outlet temperature is studied as shown in fig.9. The results show that increasing the entry section velocity leads to a reduction in the outlet temperature by way of additional energy absorbed by the absorber plate transferred to the working fluid by forced convection. Nevertheless, the time required to dissipate the energy saved from the absorber is also diminished when the inlet velocity is increased. Additionally, the entrance velocity of the system has a significant effect on the operation duration at night-shift. As shown in fig.10. The hour of operation for all types of absorbers was reduced to a half value when the inlet velocity was increased from $0.68 \mathrm{~m} / \mathrm{s}$ to $3.4 \mathrm{~m} / \mathrm{s}$. For example, water can serve for 4.31 hours 
after sunset when the inlet velocity is $0.68 \mathrm{~m} / \mathrm{s}$, while it can operate the system for a smaller period of 2.87 hours when $3.4 \mathrm{~m} / \mathrm{s}$ is used for entrance velocity.

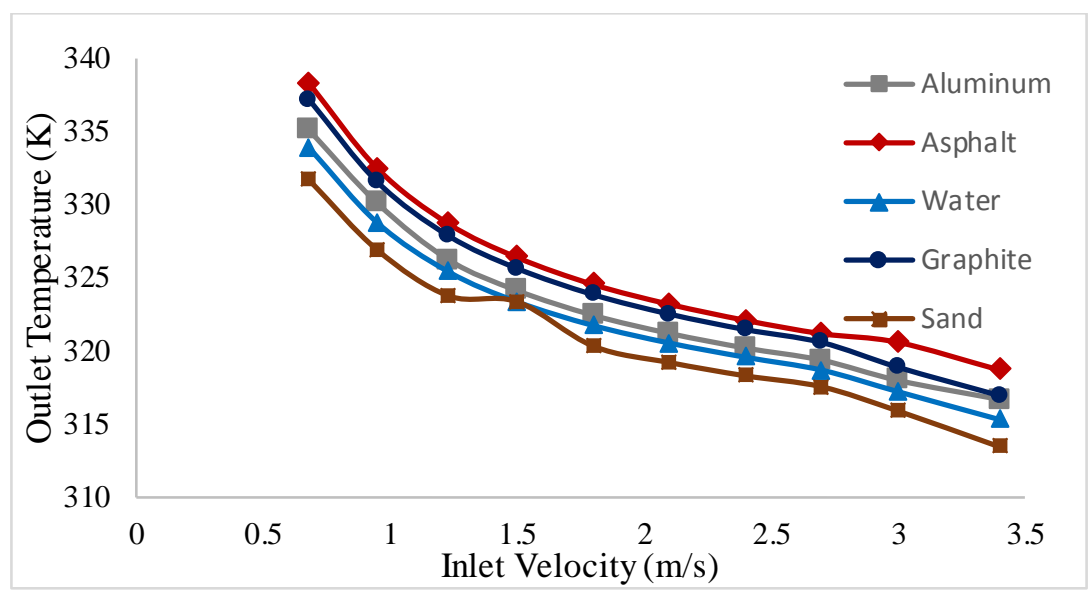

Figure 9 variation of outlet temperature verse inlet velocity

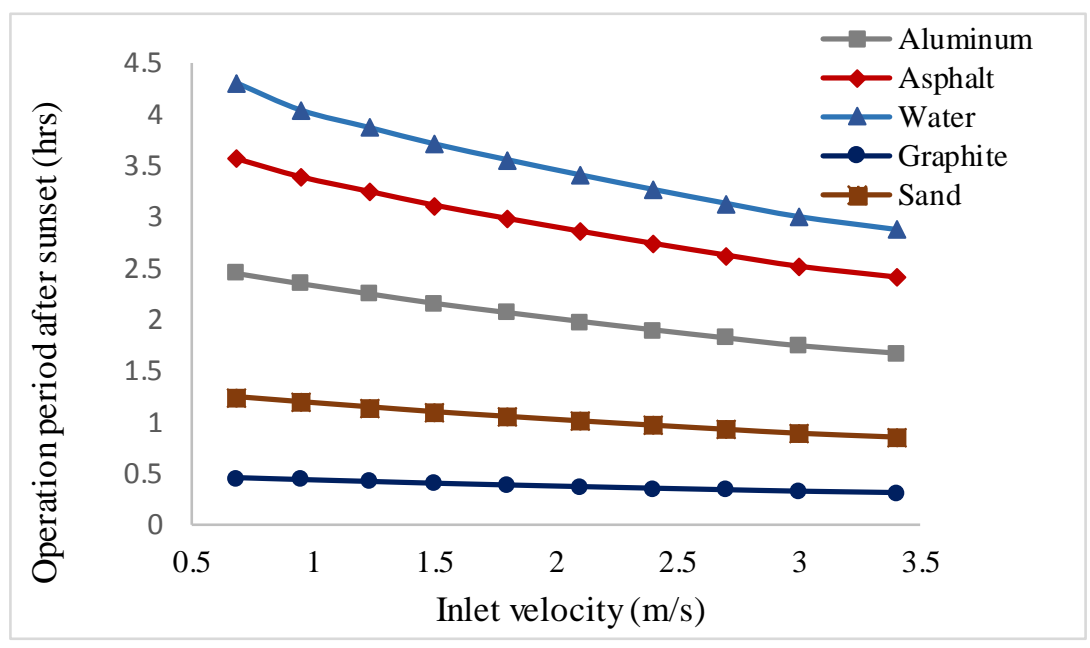

Figure 10 Operation hours after sunset for different inlet velocity.

\section{CONCLUSIONS}

In this study, a solar air heater was modeled and its performance parameters validated against experimental data and other numerical research results. Ten inlet velocity at range of $(0.68 \mathrm{~m} / \mathrm{s}$ to $3.4 \mathrm{~m} / \mathrm{s})$ was performed to optimize the most corresponding absorber for both outlet temperature and night time operation of the system using CFD Analysis. Depending on the results presented in the present investigation, the CFD prediction conclusions are described as follows:

The methodology performed to simulate the problem has shown good agreement with the results available in the literature. The results were compared with numerical and experimental studies for both Nusselt number and outlet temperature for different Reynold number and solar intensity respectively. It's a great challenge to select the 
appropriate absorber material for a SAH simulation. Therefore, the current study tested five thermal storage materials. It was achieved that the asphalt and sand yielded the best and worst results according to the outlet temperature. Then, the investigation focused on the optimum absorber for night time operation. It was found that water can operate the system for a long period, which was 4.31 hours. On the other hand, graphite loses the most absorbed energy and can run the system for the shortest time, 0.46 hours. Finally, it was concluded that increasing inlet velocity leads to reduce both outlet temperature and system duration after sunset.

\section{DECLARATION OF INTEREST}

There are no conflicts of interest reported by authors. The content of and the writing of this article are the responsibility of the authors.

\section{ACKNOWLEDGMENTS}

The authors thank ANSYS Academic for their support of the available simulation tools.

\section{REFERENCES}

Bal, L. M., et al. (2011). "Review of solar dryers with latent heat storage systems for agricultural products." Renewable and Sustainable Energy Reviews 15(1): 876-880.

Berdahl, P., et al. (2008). "Weathering of roofing materials-an overview." Construction and Building Materials 22(4): 423-433.

Bhushan, B. and R. Singh (2010). "A review on methodology of artificial roughness used in duct of solar air heaters." Energy 35(1): 202-212.

Bhushan, B. and R. Singh (2012). "Thermal and thermohydraulic performance of roughened solar air heater having protruded absorber plate." Solar energy 86(11): 3388-3396.

Chaube, A., et al. (2006). "Analysis of heat transfer augmentation and flow characteristics due to rib roughness over absorber plate of a solar air heater." Renewable Energy 31(3): 317-331.

Chaudhari, S., et al. (2014). "CFD analysis of solar air heater." Int. Journal of Engineering Research and Applications 4(6): 47-50.

Chouksey, V. K. and S. Sharma (2016). "Investigations on thermal performance characteristics of wire screen packed bed solar air heater." Solar energy 132: 591-605. 
Cortes, A. and R. Piacentini (1990). "Improvement of the efficiency of a bare solar collector by means of turbulence promoters." Applied energy 36(4): 253-261.

Duffie, J. A. and W. A. Beckman (2013). Solar engineering of thermal processes, John Wiley \& Sons.

Dutil, Y., et al. (2011). "A review on phase-change materials: mathematical modeling and simulations."

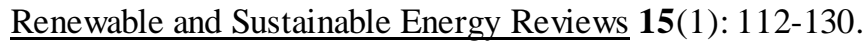

Esen, H., et al. (2009). "Modelling of a new solar air heater through least-squares support vector machines." Expert Systems with Applications 36(7): 10673-10682.

Farid, M. M., et al. (2004). "A review on phase change energy storage: materials and applications." Energy conversion and management 45(9-10): 1597-1615.

Fluent, A. (2013). "Release 15.0." Theory Guide, November.

Gawande, V. B., et al. (2014). "CFD analysis to study effect of circular vortex generator placed in inlet section to investigate heat transfer aspects of solar air heater." The Scientific World Journal 2014.

Gupta, D., et al. (1997). "Thermohydraulic performance of solar air heaters with roughened absorber plates." Solar energy 61(1): 33-42.

Ibrahim, H., et al. (2008). "Energy storage systems — Characteristics and comparisons." Renewable and Sustainable Energy Reviews 12(5): 1221-1250.

Karwa, R. and B. Maheshwari (2009). "Heat transfer and friction in an asymmetrically heated rectangular duct with half and fully perforated baffles at different pitches."International Communications in Heat and Mass Transfer 36(3): 264-268.

Kothandaraman, C. (2004). Heat and mass transfer data book, New Age International.

Kumar, R. and A. Kumar (2017). "Computational fluid dynamics based study for analyzing heat transfer and friction factor in semi-circular rib-roughened equilateral triangular duct." International Journal of Numerical Methods for Heat \& Fluid Flow 27(4): 941-957.

Kumar, S. and R. Saini (2009). "CFD based performance analysis of a solar air heater duct provided with artificial roughness." Renewable Energy 34(5): 1285-1291. 
Layek, A. (2019). 'Performance Analysis of solar air heater having absorber plate artificially roughened by chamfered-square elements."

Manglik, R. M. and A. E. Bergles(1995). "Heat transfer and pressure drop correlations for the rectangular offset strip fin compact heat exchanger." Experimental Thermal and Fluid Science 10(2): 171-180.

McEligot, D., et al. (2016). Thermal Properties of G-348 Graphite, Idaho National Lab.(INL), Idaho Falls, ID (United States).

Muhammed, H. A. and S. A. Atrooshi (2019). "Modeling solar chimney for geometry optimization." Renewable Energy 138: 212-223.

Naphon, P. (2005). "On the performance and entropy generation of the double-pass solar air heater with longitudinal fins." Renewable Energy 30(9): 1345-1357.

Ozgen, F., et al. (2009). "Experimental investigation of thermal performance of a double-flow solar air heater having aluminium cans." Renewable Energy 34(11): 2391-2398.

Pashchenko, D. (2018). "ANSYS fluent CFD modeling of solar air-heater thermoaerodynamics." Applied Solar Energy 54(1): 32-39.

Piao, Y., et al . (1994). "Forced convective heat transfer in cross-corrugated solar air heaters."

Pretorius, J. P. (2007). Optimization and control of a large-scale solar chimney power plant, Stellenbosch: University of Stellenbosch.

Priyam, A. and P. Chand (2016). "Thermal and thermohydraulic performance of wavy finned absorber solar air heater." Solar energy 130: 250-259.

Py, X., et al. (2001). "Paraffin/porous-graphite-matrix composite as a high and constant power thermal storage material." International journal of heat and mass transfer 44(14): 2727-2737.

Qader, B.S., et al. (2019). "Numerical investigation of flow through inclined fins under the absorber plate of solar air heater." Renewable Energy 141: 468-481.

Qader, B.S., et al. (2019). "RSM approach for modeling and optimization of designing parameters for inclined fins of solar air heater." Renewable Energy 136: 48-68. 
Rai, S., et al. (2018). "Evaluation of thermo hydraulic effect on offset finned absorber solar air heater." Renewable Energy 125: 39-54.

Sahu, M. K. and R. K. Prasad (2016). "Exergy based performance evaluation of solar air heater with arcshaped wire roughened absorber plate." Renewable Energy 96: 233-243.

Saini, R. and S. Singal (2007). "A review on roughness geometry used in solar air heaters." Solar energy 81(11): 1340-1350.

Schlipf, D., et al. (2015). "Using sand and other small grained materials as heat storage medium in a packed bed HTTESS." Energy Procedia 69: 1029-1038.

Tyagi, V., et al. (2012). "Review on solar air heating system with and without thermal energy storage system." Renewable and Sustainable Energy Reviews 16(4): 2289-2303.

Wadhawan, A., et al. (2018). "Analysis of the effects of use of thermal energy storage device (TESD) in solar air heater." Alexandria engineering journal 57(3): 1173-1183.

Xie, G., et al. (2013). "Numerical analysis of flow structure and heat transfer characteristics in square channels with different internal-protruded dimple geometrics." International journal of heat and mass transfer 67: 81-97.

Yadav, S. and M. Kaushal (2013). "Nusselt number and friction factor correlations for solar air heater duct having protrusions as roughness elements on absorber plate." Experimental Thermal and Fluid Science 44: 3441.

Zamora, B.and A. Kaiser (2009). "Optimum wall-to-wall spacing in solar chimney shaped channels in natural convection by numerical investigation." Applied Thermal Engineering 29(4): 762-769. 